\title{
Biemond syndrome type 2
}

INSERM

\section{Source}

INSERM. (1999). Orphanet: an online rare disease and orphan drug data base. Biemond syndrome type 2. ORPHA:141333

Biemond syndrome type 2 (BS2) is a rare genetic neurological and developmental disorder reported in a very small number of patients with a poorly defined phenotype which includes iris coloboma, short stature, obesity, hypogonadism, postaxial polydactyly, and intellectual disability. Hydrocephalus and facial dysostosis were also reported. BS2 shares features with Bardet-Biedl syndrome. There have been no further descriptions in the literature since 1997. 